\title{
Building Feedback Rating-based Reputation System for Trusted Delivery of Cloud Services
}

\author{
Chao Yan, Lianyong Qi, Jiancheng Ni \\ College of Computer Science \\ Qufu Normal University \\ Rizhao, China \\ firebird.yan@gmail.com
}

\begin{abstract}
Due to the open and dynamic nature of cloud environment, the service quality of a cloud service is not always trusted as advertised by cloud provider. Feedback rating-based reputation system is an effective approach to determine the trust of a cloud service. Unfortunately, a comprehensive reputation system is absent from present major cloud providers and not supported by present major cloud providers, e.g., Amazon, Google and Microsoft, which hampers a cloud user from selecting a trusted cloud service. In view of this challenge, in this paper, we first study why reputation system is absent from cloud, from perspectives of cloud provider and cloud user respectively. Afterwards, taking e-Commerce experience for reference, we put forward a novel reputation system tailored to cloud service delivery, i.e., R3 (Rating-Review-based Reputation system, $\mathrm{R3})$. The proposed $\mathrm{R3}$ is scalable towards more personalized cloud delivery applications, and can be easily integrated into the present cloud architecture.
\end{abstract}

Keywords- Trust; Feedback rating; Reputation system; Service quality; cloud service

\section{INTRODUCTION}

As the natural evolution of Service Computing, Cloud Computing has recently gained more and more attentions from both industrial and academic areas [1-2]. Through selecting and integrating various cloud services, a user can deploy his/her business applications economically and conveniently. However, due to the open and dynamic nature of cloud environment, the service quality of a cloud service is not always trusted as advertised by cloud provider [3]. Therefore, it is of great significance to build trust between cloud user and cloud provider.

Feedback rating is considered as an effective manner to measure the trust of a cloud service. After a user invoked a cloud service, he/she can leave a positive or negative rating (1-star to 5-stars) or review, towards the service's overall quality performance. With the historical feedback ratings, we can measure the service reputation and predict the future service quality more accurately. However, to the best of our knowledge, such a reputation system is absent from major cloud platforms [4], e.g., Amazon, Google and Microsoft, which hampers a user from selecting a trusted cloud service. In view of this challenge, in this paper, we put forward a reputation system tailored to cloud service delivery, i.e., R3 (Rating-Review-based Reputation system, R3).

The remainder of this paper is organized as below. In Section2, we analyze the reasons that reputation system is absent from cloud. In Section3, we put forward a novel reputation system R3 tailored to cloud service delivery. Related work and comparison analyses are introduced in Section4, and finally in Section5, we conclude the paper and point out future research directions.

\section{ABSENCE OF REPUTATION SYSTEM FROM CLOUD: REASONS ANALYSES}

In this section, we analyze the reasons that reputation system is absent from cloud, from the perspectives of cloud provider and cloud user respectively.

\section{A. Reasons from cloud providers}

1) Overconfidence in delivered service quality.

The big cloud provider, e.g., Amazon is usually of rich experience in services delivery to public, and owns advanced techniques to assure the service quality. Therefore, a cloud provider often has overconfidence in its delivered service quality, and regards it unnecessary to build a reputation system for its cloud services. Instead, a compensation mechanism is recruited when the promised SLA (Service Level Agreement) contract is violated. For example, as in Fig .1, Amazon declares a service availability of $99.99 \%$ in its SaaS SLA contract, and different compensation rates are available if SLA is violated [5].

\begin{tabular}{|c|c|}
\hline \multicolumn{2}{|l|}{ Service Level Agreement } \\
\hline \multicolumn{2}{|l|}{ Availability } \\
\hline \multicolumn{2}{|l|}{$\bullet 99.99 \%$ uptime } \\
\hline \multicolumn{2}{|l|}{ Compensation } \\
\hline \multicolumn{2}{|c|}{ - Percentage of total charges paid by cloud user } \\
\hline UPTIME (PER 15 MIN) & COMPENSATION \\
\hline $99.99 \%-100 \%$ & $0 \%$ \\
\hline $98.00 \%-99.98 \%$ & $5 \%$ \\
\hline $97.00 \%-97.99 \%$ & $10 \%$ \\
\hline $95.00 \%-96.99 \%$ & $20 \%$ \\
\hline$<95.00 \%$ & $50 \%$ \\
\hline
\end{tabular}

Figure 1. An example of SLA agreement

2) Fear for malicious ratings towards cloud services.

Generally, feedback rating-based reputation system is regarded as a promising way to measure the trust of various web services. However, this kind of reputation system cannot always work well, as a good reputation accumulated within a long time period could be easily 
damaged by a malicious rating. Therefore, from the perspective of cloud provider, it is better to leave the reputation system empty.

\section{B. Reasons from Cloud Users}

1) Hard to monitor the necessary QoS data for rating.

In cloud environment, users' business applications are deployed and executed on the remote servers, not locally. Therefore, a cloud user has little control on his/her business execution, and thereby cannot monitor the detailed runtime QoS data, e.g., the actual disk I/O, response time. Although several toolkits have been developed to monitor the QoS data of cloud service, e.g., Amazon CloudWatch [6], the monitoring range is limited and the monitoring cost is expensive. Therefore, it is hard for a cloud user to rate a cloud service, based on the little monitored QoS data.

2) Hard to rate a cloud service in service combination instance.

Generally, a cloud provider delivers its services in the form of combination. For example, Table 1 lists four combinations of cloud services advertised by Amazon EC2 [7], i.e., \{Small instance, Middle instance, Large instance and Extra-large instance $\}$, where each instance is a combination of four cloud services \{Memory, EC2 computing unit, Local storage, Platform $\}$. In this situation, a cloud user can only rate the whole service combination after service delivery. For example, a cloud user gives a '4-star' rating to service combination 'Middle instance' in Table 1; obviously, this '4-star' rating is a global rating towards the overall quality of combination (i.e., Middle instance), not a local rating towards a single cloud service (e.g., 410 GB Local storage in Middle instance). Therefore, this 'global feedback rating' cannot help guide the selection of 'single cloud service'.

It mainly consists of three components, i.e., User rating, User review and Delivered times (times that a service is invoked). Indeed, R3 integrates all the advantages of e-Commerce reputation systems, and considers the reasons in Section2.

TABLE I. AN EXAMPLE OF CLOUD SERVICE COMBINATION

\begin{tabular}{|l|l|l|l|l|}
\hline $\begin{array}{c}\text { Service } \\
\text { type } \\
\text { Instance } \\
\text { type }\end{array}$ & $\begin{array}{l}\text { Memory } \\
\text { (GiB) }\end{array}$ & $\begin{array}{l}\text { EC2 } \\
\text { Compu } \\
\text { ting } \\
\text { Unit }\end{array}$ & $\begin{array}{l}\text { Local } \\
\text { Storage } \\
\text { (GB) }\end{array}$ & $\begin{array}{l}\text { Platform } \\
\text { (bit) }\end{array}$ \\
\hline Small & 1.7 & 1 & 160 & 32 or 64 \\
\hline Middle & 3.75 & 2 & 410 & 32 or 64 \\
\hline Large & 7.5 & 4 & 850 & 64 \\
\hline $\begin{array}{l}\text { Extra- } \\
\text { large }\end{array}$ & 15 & 8 & 1690 & 64 \\
\hline
\end{tabular}

\section{A REPUTATION SYSTEM IN CLOUD: R3.}

\section{A. Architecture of cloud service delivery}

Here, we first introduce a three-layer architecture of cloud service delivery as in Fig .2, which consists of three parties involved, i.e., Cloud user, Cloud provider and
Trusted third party. Here, a neutral-Trusted third party is proposed to collect the necessary information associated with cloud service delivery, so as to build a fair reputation system for both cloud user and cloud provider.

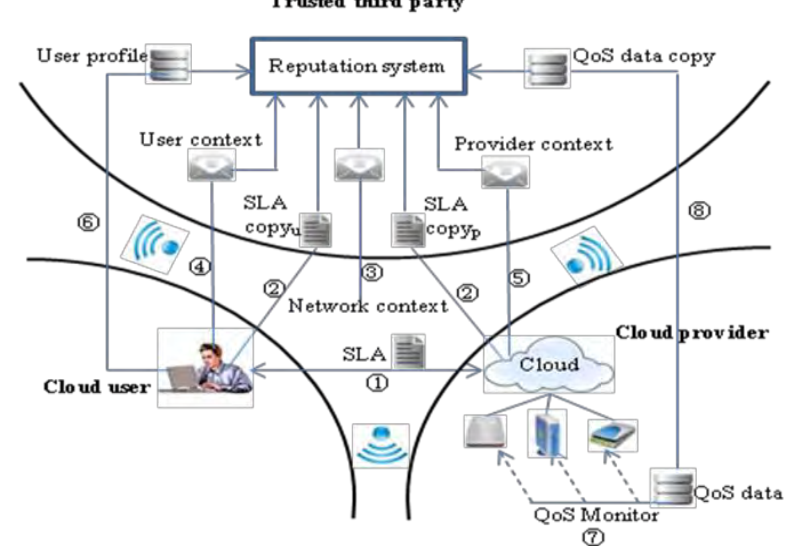

Figure 2. A three-layer architecture of cloud service delivery.

Next, we introduce some important inputs for reputation system, and tell how to obtain them through the eight steps demonstrated in Fig .2.

- SLA contract. A SLA contract should be reached between a cloud user and a cloud provider (step1), before a cloud service is delivered. This contract specifies the responsibilities and obligations of both sides, including: 'Which cloud service (or service combination as in Table 2) is delivered?', 'What is the expected QoS?', 'What is the compensation rate if SLA is violated?', and so on. Please note that two SLA copies are available, i.e., SLA copyu and SLA copyp, which are sent by cloud user and cloud provider respectively (step2). If SLA copyu $=$ SLA copyp holds, neither cloud user nor cloud provider cheats; otherwise, Trusted third party finds the cheated one and announce the other.

- Network context. Network plays an important role in cloud service delivery. For example, a smaller network latency and a larger network transfer rate may lead to a faster $I / O$ speed in cloud. Therefore, for objective quality estimation, network context should be monitored by Trusted third party (step3).

- User context. User context has a direct impact on the quality of remote cloud service. For example, for the same cloud user, he/she may receive a quick response from Google email via a powerful laptop; while if he/she uses a lightweight smart phone, the waiting time may become too long to stand (step4).

- Provider context. Likewise, provider context also has an inherent impact on the cloud service quality. For example, a sudden burst of cloud load may bring a lower execution efficiency and disappoints the cloud user (step5).

- User profile. User rating towards cloud service is rather subjective; therefore, user profile is also an important input for reputation system. Here, user profile includes some personal information (e.g., user ID and user type), QoS criteria concerned 
(e.g., latency and scalability) and QoS preference (e.g., a user prefers latency to scalability) (step6).

- Monitored QoS data. The actually delivered QoS is the direct evaluation basis for a cloud user to rate a cloud service. Through some monitoring tools, e.g., CloudWatch [6], we can monitor the actually delivered QoS of a cloud service (or a service combination instance). After monitoring (step7), the derived QoS data is sent to reputation system (step8), which could be recruited to judge whether a SLA contract is violated.

TABLE II. REPUTATION SYSTEM R3: MEANING \& SPECIFICATION

\begin{tabular}{|c|c|c|c|}
\hline \multicolumn{2}{|c|}{$\mathrm{Type}_{\text {Typem }}^{\text {Item }}$} & \multirow[b]{2}{*}{$\begin{array}{l}\text { Cloud user's rating towards overall } \\
\text { quality of cloud service }\end{array}$} & \multirow[b]{2}{*}{ 1-star to 5-star } \\
\hline \multirow{10}{*}{$\begin{array}{l}\text { User } \\
\text { rating }\end{array}$} & Overall rating & & \\
\hline & Detailed rating & $\begin{array}{l}\text { More detailed observation of the cloud } \\
\text { service quality }\end{array}$ & $\begin{array}{l}\text { Only for QoS criteria concerned in User } \\
\text { profile. }\end{array}$ \\
\hline & Period rating & $\begin{array}{l}\text { Leave a rating after each time period, } \\
\text { to accommodate the quality change of } \\
\text { a cloud service }\end{array}$ & $\begin{array}{l}\text { Divide the lifecycle of a cloud service into } \\
\text { several time periods, and rate per period. E.g., } \\
\text { rate once per month }\end{array}$ \\
\hline & Mutual rating & $\begin{array}{l}\text { Cloud user and cloud provider can } \\
\text { rate each other }\end{array}$ & $\begin{array}{l}\text { Cloud provider can only rate cloud user as } \\
\text { 'Positive' or 'Neutral', so as to reduce cloud } \\
\text { user's fear for rating. }\end{array}$ \\
\hline & Timely rating & $\begin{array}{l}\text { Capture timely use experience of } \\
\text { cloud user }\end{array}$ & $\begin{array}{l}\text { Set a default rating deadline, e.g., } 30 \text { days } \\
\text { after delivery. }\end{array}$ \\
\hline & $\begin{array}{l}\text { Revisable } \\
\text { rating }\end{array}$ & $\begin{array}{l}\text { Accommodate the quality change of a } \\
\text { cloud service }\end{array}$ & $\begin{array}{l}\text { Keep records of the revised ratings and } \\
\text { reasons. }\end{array}$ \\
\hline & $\begin{array}{l}\text { NO } \\
\text { Non-user rating }\end{array}$ & $\begin{array}{l}\text { Ensure the authenticity of feedback } \\
\text { rating }\end{array}$ & Non-user is not allowed to leave a rating. \\
\hline & $\begin{array}{l}\text { NO } \\
\text { repeated } \\
\text { rating }\end{array}$ & Ensure the rating fairness & $\begin{array}{l}\text { Exclude the repeated ratings in a time period } \\
\text { from an identical cloud user }\end{array}$ \\
\hline & $\begin{array}{l}\text { NO } \\
\text { Malicious rating }\end{array}$ & Ensure the rating fairness & $\begin{array}{l}\text { Eliminate malicious rating by provider's } \\
\text { rating towards user }\end{array}$ \\
\hline & $\begin{array}{l}\text { NO } \\
\text { Mandatory rating }\end{array}$ & Respect user's willingness & $\begin{array}{l}\text { Set a default rating for cloud users with no } \\
\text { feedback. }\end{array}$ \\
\hline \multirow{4}{*}{$\begin{array}{l}\text { User } \\
\text { review }\end{array}$} & Timely review & $\begin{array}{l}\text { Capture timely use experience of } \\
\text { cloud user }\end{array}$ & $\begin{array}{l}\text { Set a default rating deadline, e.g., } 30 \text { days } \\
\text { after delivery }\end{array}$ \\
\hline & Revisable review & $\begin{array}{l}\text { Accommodate the quality change of a } \\
\text { cloud service }\end{array}$ & $\begin{array}{l}\text { Keep records of the revised reviews and } \\
\text { reasons. }\end{array}$ \\
\hline & Rating for review & $\begin{array}{l}\text { Measure the trustworthiness of a } \\
\text { review }\end{array}$ & 'Helpful' or 'not Helpful' \\
\hline & $\begin{array}{l}\text { NO } \\
\text { Malicious review }\end{array}$ & Ensure the review fairness & $\begin{array}{l}\text { Eliminate malicious review by rating for } \\
\text { review }\end{array}$ \\
\hline \multicolumn{2}{|c|}{ Delivered times } & $\begin{array}{l}\text { Another trust measurement to cloud } \\
\text { service quality }\end{array}$ & $\begin{array}{l}\text { Set a default time period for quantity } \\
\text { statistics, e.g., } 1 \text { year. }\end{array}$ \\
\hline
\end{tabular}




\section{B. A Rating-Review-based Reputation system: R3}

In this subsection, we introduce a reputation system tailored to cloud service delivery, i.e., R3 in Table 2. It mainly consists of three components, i.e., User rating, User review and Delivered times (times that a service is invoked). Indeed, R3 integrates all the advantages of eCommerce reputation systems, and considers the reasons in Section2.

The suggestions in Table 2 can help build the trust between cloud users and cloud providers, and can overcome the difficulties introduced in Section2. Concretely, 'NO Malicious rating', 'NO Non-user rating', 'Mutual rating', 'Rating for review' and 'NO Malicious reviews' can help to minimize users' fear for malicious ratings; 'Overall rating' and 'Detailed rating' can help to rate a cloud service in service combinations; 'Period rating', 'Timely rating' and 'Timely review' are tailored to the long running period of cloud services; while 'Revisable rating', 'NO Repeated rating', 'NO Mandatory rating', 'Revisable review' and 'Delivered times' ensure the accuracy of feedback ratings.

\section{RELATED WORK AND COMPARISON ANALYSES}

Feedback rating is an effective manner to build trust between cloud users and cloud providers. To collect user feedbacks, a Trust Feedback Collector is proposed in [8]. A feedback rating-based trust calculation method, i.e., TrustCalculator is introduced in [9], to predict the future quality of a cloud service. However, the recruited user rating is of rather simple, i.e., from 0 to 5 , which cannot accommodate the complicated cloud service delivery. As user rating is highly context-aware, a context-aware trust concept in Social Cloud is introduced in [10]; while more detailed classification of context is absent from the paper. A method is proposed in [11] to detect the malicious ratings, by comparing the monitored QoS and the expected quality in SLA. However, some QoS data is hard to monitor. In view of the above shortcomings, a novel reputation system R3 is proposed in this paper, to better accommodate the characteristics of cloud service delivery.

\section{CONCLUSIONS}

Feedback rating-based reputation system is a promising way, to build trust between cloud user and cloud provider. However, a comprehensive reputation system is absent from present major cloud providers. In view of this challenge, in this paper, we analyze the reasons that a reputation system is absent from cloud, and put forward a novel reputation system R3 tailored to cloud service delivery. Although not perfect, we argue that R3 is a good alternative to support trusted cloud service delivery, as it considers both the cloud characteristics and the advantages of e-Commerce reputation systems. In the future, we will continue to refine the proposed $\mathrm{R} 3$ reputation system, by adding more concrete and quantitative reputation calculation process.

\section{ACKNOWLEDGMENT}

This paper is supported by the Research on Application Strategy of E-government Cloud from the Aspect of Top Level Design-Illustrated by the case of Shandong Peninsula Blue Economic Zone (No: 2013RKB01040), Jining science and technology development plan, the Open Project of State Key Lab. for Novel Software Technology (No. KFKT2012B31), Natural Science Foundation of Shandong Province of China (No.ZR2012FQ011), SRI of SPED (No.J12LN06), DRF and UF (BSQD20110123, XJ201227) of QFNU.

\section{REFERENCES}

[1] Wei She, I-Ling Yen, Bhavani Thuraisingham and San-Yih Huang, Rule-Based Run-Time Information Flow Control in Service Cloud, IEEE International Conference on Web Services, 2011, pp. 524 531

[2] X. Zhang, T. Yang, C. Liu and J. Chen, A Scalable Two-Phase Top-Down Specialization Approach for Data Anonymization using MapReduce on Cloud, IEEE Transactions on Parallel and Distributed Systems 25(2014) 363-373

[3] Chunming Rong, Son T. Nguyen and Martin Gilje Jaatun, Beyond lightning: A survey on security challenges in cloud computing, Computers and Electrical Engineering 39 (2013) 47-54

[4] Sheikh Mahbub Habib, Sebastian Ries and Max Mühlhäuser, Cloud Computing Landscape and Research Challenges regarding Trust and Reputation, Symposia and Workshops on Ubiquitous, Autonomic and Trusted Computing, 2010,pp.410-415

[5] Noura Limam and Raouf Boutaba. Assessing Software Service Quality and Trustworthiness at Selection Time. IEEE Transactions on Software Engineering 36 (2010) 559-574

[6] CloudWatch, For further detail, please visit our website, http://aws.amazon.com/cloudwatch/,, 2013

[7] EC2, For further detail, please visit our website, http://aws.amazon.com/cn/ec2/, 2013

[8] Talal H. Noor, Quan Z. Sheng, Sherali Zeadally and Jian Yu, Trust Management of Services in Cloud Environments: Obstacles and Solutions, ACM Computing Surveys 46 (2013) 1-35

[9] Monoj Kumar Muchahari and Smriti Kumar Sinha, A New Trust Management Architecture for Cloud Computing Environment, International Symposium on Cloud and Services Computing, 2012, pp.136-140

[10] Simon Caton, et al, Foundations of Trust: Contextualising Trust in Social Clouds, In Proceedings of 2rd International Conference on Cloud and Green Computing, 2012, pp. 424-429

[11] S. Wang, Q. Sun, H. Zou and F. Yang, Reputation measure approach of web service for service selection, IET Software 5(2011) 466-473 